\title{
Crescimento, produtividade, uso eficiente da água e custos produtivos do amendoim
}

\section{BR1}

Growth, productivity, efficient use of water and productive costs of peanut BR1

Crecimiento, productividad, uso eficiente del agua y costos de producción de maní BR1

Fernando Antônio Melo da Costa

ORCID: https://orcid.org/0000-0003-3092-3618

Universidade Federal de Campina Grande, Brasil E-mail: fmelodacosta@gmail.com

Júlia Soares Pereira

ORCID: https://orcid.org/0000-0002-6495-1169

Universidade Federal de Campina Grande, Brasil E-mail: julia_eng@hotmail.com

José Renato Cortez Bezerra

ORCID: https://orcid.org/0000-0001-9654-9791 Empresa Brasileira de Pesquisa Agropecuária, Brasil E-mail: jose.cortez-bezerra@embrapa.br

José Dantas Neto

ORCID: https://orcid.org/0000-0003-0798-6717 Universidade Federal de Campina Grande, Brasil E-mail: zedantas1955@gmail.com

Viviane Farias Silva

ORCID: https://orcid.org/0000-0002-5891-0328

Universidade Federal de Campina Grande, Brasil E-mail: flordeformosur@hotmail.com

\begin{abstract}
Resumo
Com o déficit hídrico em regiões semiáridas, pesquisas buscando alternativas no manejo de água e solo, visando a eficiência e produtividade da cultura do amendoim vêm sendo tópicos de preocupações dos pesquisadores, para amenizar as consequências das secas prolongadas e maneiras de conviver com a seca. Nesse contexto, a presente pesquisa foi realizada objetivando-se avaliar o crescimento, produtividade, uso eficiente da água e custos produtivos do amendoim BR-1. O experimento foi conduzido em campo no município de Petrolândia -PE, região semiárida do Nordeste brasileiro. Foi utilizado o delineamento experimental de blocos ao acaso e as parcelas foram dispostas em faixa em 4 repetições, com o preparo de solo disposto na parcela principal e lâminas de irrigação nas parcelas secundárias, assim distribuídas. Para os preparos de solo foram utilizados: Preparo do solo com arado de discos seguido de grade niveladora (SP1); Preparo do solo com grade aradora (SP2); Preparo do solo com arado escarificador seguido de grade niveladora (SP3); Preparo do solo com arado escarificador seguido de grade aradora (SP4). As lâminas de irrigação utilizadas foram: 50, 75, 100 e 125\% da necessidade hídrica da cultura (ETc). Foram analisados a altura de planta, diâmetro de caule, vagens chocas, porcentagem de grãos, peso e 100 grãos e produção do amendoim com e sem cascas no $1^{\circ}$ e $2^{\circ}$ ciclo, custos e receita liquida. A lâmina de $75 \%$ ETc teve maior altura de planta aos 60 DAE, com cerca de $20 \mathrm{~cm}$ e SP2 com lâminas de $100 \%$ ETc tiveram $28 \%$ de porcentagem de vagens com 2 grãos, no $1^{\circ}$ ciclo.
\end{abstract}

Palavras-chave: Produtividade; Eficiência de uso da água; Mecanização.

\begin{abstract}
Arachis Hypogaea L. has a strong economic importance in Brazil, being used in the in natura form and in the production of its derivatives as oils, pastes and bullets. The municipality of Petrolândia in the state of Pernambuco, located in the semi-arid region of the Northeast, presents climatic characteristics conducive to the good development of the crop with temperature in the range of 28 to $32{ }^{\circ} \mathrm{C}$. The objective of this work was to analyze the growth of peanut crop, cultivar BR1, for different soil preparation systems as a function of the water slides, and the influence of these parameters on productivity. The efficient use of water and the cost benefit of production in the region were evaluated. The work was done using the experimental design of randomized blocks and the plots were arranged in strip in 4 replications, with the preparation of soil arranged in the main plot and irrigation slides in the secondary plots, thus distributed. Soil preparation was done using Disk Plow, Harrow, Scarifier and Leveling Grate. The irrigation slides were used considering 50,75, 100 and $125 \%$ of the water requirement of the culture. The consecutive increase of the irrigation slides showed an increase in productivity. Soil preparation systems did not show a significant
\end{abstract}


increase in production. The higher efficiency of water use was observed with the $50 \%$ slide. The best cost benefit was identified in the preparation with scarifier + leveler with the $100 \%$ ETc blade.

Keywords: Productividad; Eficiencia en el uso del agua; Mecanización.

\section{Resumen}

Con el déficit hídrico en las regiones semiáridas, las investigaciones que buscan alternativas en el manejo del agua y el suelo, con el objetivo de la eficiencia y productividad de los cultivos de maní, han sido temas de preocupación para los investigadores, para paliar las consecuencias de sequías prolongadas y formas de vivir con la sequía. En este contexto, esta investigación se realizó con el objetivo de evaluar el crecimiento, la productividad, el uso eficiente del agua y los costos de producción del maní BR-1. El experimento se realizó en campo en la ciudad de Petrolândia -PE, región semiárida del noreste de Brasil. Se utilizó un diseño experimental de bloques al azar y las parcelas se dispusieron en una franja en 4 repeticiones, con la preparación del suelo dispuesta en la parcela principal y las profundidades de riego en las parcelas secundarias, distribuidas de esta manera. Para las preparaciones del suelo se utilizó lo siguiente: preparación del suelo con un arado de disco seguido de una rastra niveladora (SP1); Preparación del suelo con rastra (SP2); Preparación del suelo con arado escarificador seguido de rastra niveladora (SP3); Preparación del suelo con arado escarificador seguido de rastra (SP4). Las profundidades de riego utilizadas fueron: 50, 75, 100 y $125 \%$ del requerimiento hídrico del cultivo (ETc). Se analizó altura de planta, diámetro de tallo, vainas de eclosión, porcentaje de grano, peso y 100 granos y producción de maní con y sin cáscara en el 1er y 2do ciclo, costos e ingresos netos. La hoja $75 \%$ ETc tuvo la altura de planta más alta a los 60 DAE, con aproximadamente 20 $\mathrm{cm}$, y SP2 con hojas $100 \%$ ETc tuvo $28 \%$ de porcentaje de vainas con 2 granos, en el 1 er ciclo.

Palabras clave: Productividad; Eficiencia en el uso del agua; Mecanización.

\section{Introdução}

A região do nordeste brasileiro é caracterizada pelo solo raso e pedregoso, clima semiárido, com precipitações irregulares e má distribuída, com épocas de secas prolongadas. Têm locais com índices pluviométricos abaixo de 800 mm/ano, ocasionando problemas socioeconômicos, sendo a água fator limitante para desenvolvimento da agricultura e pecuária na região, bem como estimula o êxodo rural (Marengo et al., 2011).

Com o déficit hídrico em regiões semiáridas, pesquisas buscando alternativas no manejo de água e solo, visando a eficiência e produtividade da cultura vêm sendo tópicos de preocupações dos pesquisadores, instituições públicas e privadas, para amenizar as consequências das secas prolongadas e maneiras de conviver com a seca. Pinheiro et al. (2014), afirmam que a agricultura nestas regiões deve ser realizada de forma sustentável e com utilização de espécies adaptadas as condições edafoclimáticas.

A irrigação é aplicada para fornecer à cultura a quantidade de água necessária ao seu desenvolvimento na quantidade adequada e no momento oportuno, uma vez que a deficiência hídrica ou excesso de água pode se tornar um fator de insucesso, tanto pela menor produtividade como pelo uso ineficiente da água (Bilibio et al., 2010).

Com a crescente demanda de uso de sistemas de irrigação e de preparo do solo, quando realizados de maneira inadequada pode ocasionar danos a cultura com redução de sua produção, como também impactos ambientais. Carvalho et al. (2012,) relatam que os tipos de sistemas de preparo do solo ocasionam mudanças na estrutura física do solo. O aumento da densidade do solo é resultado das modificações da estrutura física do solo, segundo Montanari et al. (2012), havendo adulteração de porosidade, retenção de água, aeração e resistência do solo à penetração das raízes.

Com a evolução da colheita mecanizada e o crescente melhoramento de cultivares mais produtivas e com ciclo reduzido, tem-se aumentado as áreas cultivadas, desta forma, os produtores de amendoim buscam cada vez mais a inserção de tecnologias que reduzam o tempo e a mão-de-obra na produção Fachin et al. (2014).

No Brasil na safra de 2016/2017 foram produzidos cerca 466.200 toneladas de amendoim e na safra 2017/2018 teve acréscimo de 10,2\%, totalizando 513.700 t, com incremento da área plantada em algumas regiões e redução em outras, devido a disponibilidade hídrica. No Centro-Sul a produtividade média foi de $3.800 \mathrm{~kg} \cdot \mathrm{ha}-1$, no Norte/Nordeste foi de $1.068 \mathrm{~kg} \cdot \mathrm{ha}-1$ (CONAB, 2018). 
Na região do submédio do Rio São Francisco, o amendoim é plantado sob regime de irrigação, embora da forma com que o sistema de produção é conduzido, o rendimento e a rentabilidade é bem inferior a expectativa de uma cultura sob regime de irrigação, dentre outros fatores pelo uso de maquinário excessivamente pesado para o preparo de solo, assim como a irrigação sem nenhum critério técnico. O preparo do solo quando bem executado favorece a germinação, o desenvolvimento e crescimento da cultura, mas quando realizado inadequadamente pode prejudicar o desenvolvimento adequado das raízes e consequentemente a produção (Silva et al., 2000).

Nesse contexto, a presente pesquisa foi realizada objetivando-se avaliar o desenvolvimento, uso eficiente da água e custo de produção para duas épocas de cultivo do amendoim submetido a níveis de irrigação e sistemas de preparo convencional do solo.

\section{Metodologia}

\section{Local de condução do experimento}

O trabalho foi conduzido em área experimental da empresa Cofco International em convênio com a Embrapa Algodão, no município de Petrolândia - PE, nas seguintes coordenadas geográficas: latitude $08^{\circ} 56^{\prime} 41.99^{\prime}$ ' S; longitude $38^{\circ} 10^{\prime}$ 37.52 ', W e altitude $280 \mathrm{~m}$, Figura 1.

Figura 1. Mapa da localização do município Petrolândia - PE.

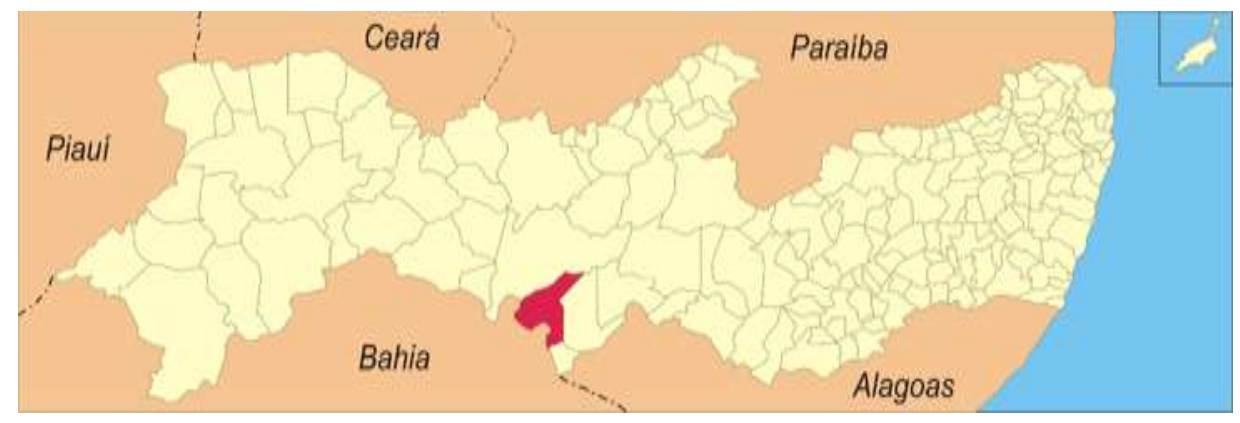

Fonte: Costa, F. A. M.

\section{Tratamentos e Delineamento Experimental}

Para avaliar os efeitos dos diferentes sistemas de preparo convencional de solo e das lâminas de irrigação sobre o amendoim BR1, foi utilizado o delineamento experimental de blocos ao acaso, com as parcelas dispostas em faixa com 4 repetições, com o preparo de solo disposto na parcela principal e as lâminas de irrigação nas parcelas secundárias:

Para o sistema de preparo convencional do solo foram aplicados os seguintes tratamentos:

SP1 - Preparo do solo com arado de discos seguido de grade niveladora;

SP2 - Preparo do solo com grade aradora;

SP3 - Preparo do solo com arado escarificador seguido de grade niveladora;

SP4 - Preparo do solo com arado escarificador seguido de grade aradora;

As lâminas de irrigação aplicadas foram: L1 - Aplicação de 50\% da ETc; L2 - Aplicação de 75\% da ETc; L3 Aplicação de $100 \%$ da ETc; L4 - Aplicação de $125 \%$ da ETc.

Cada parcela experimental ocuparam uma área de 8 x 6 m (48 m2). Devido à configuração do sistema de irrigação o preparo do solo foi executado no sentido longitudinal da área, possibilitando a formação de faixas de preparos e de irrigação contemplando todos os preparos de solo, conforme Figura 2. 
Figura 2. Croqui de montagem do experimento.

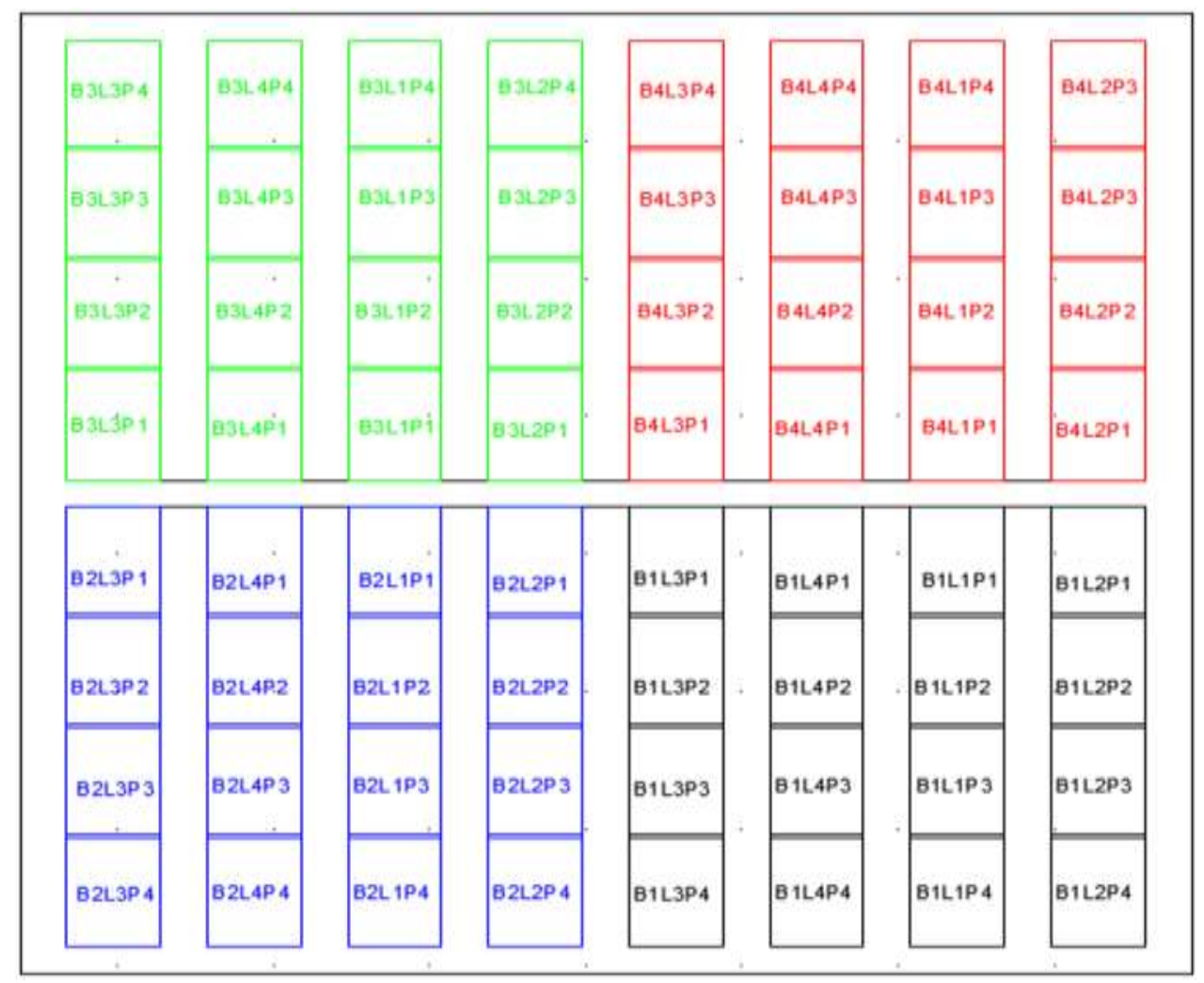

Fonte: Costa, F. A. M.

\section{Insumos utilizados}

- Sementes de amendoim BR-1;

- A adubação de fundação foi efetuada por ocasião do plantio, aplicando-se $15 \mathrm{~kg} \cdot \mathrm{ha}-1 \mathrm{de} \mathrm{N}, 80 \mathrm{~kg} \cdot \mathrm{ha}-1 \mathrm{de}$ P2O5 e 20 $\mathrm{kg} \cdot \mathrm{ha}-1$ de K2O, utilizando-se como fonte do nutriente, o MAP e o cloreto de potássio, respectivamente;

- Para o controle de ervas daninhas, foi efetuada a aplicação do herbicida Plateau em pré-emergência utilizando-se a dosagem de 140 g p.c ha-1;

- O solo foi classificado como Neossolo Quartzarênicos Órticos, textura arenosa (ARAÚJO FILHO et al., 2000).

\section{Irrigação}

A irrigação do experimento foi efetuada utilizando-se o sistema de irrigação por microaspersão, utilizando-se um espaçamento quadrado de $5 \mathrm{~m}$ de lado. A quantificação da lâmina de irrigação a ser aplicada foi efetuada tomando-se por base as características físico-hidricas do solo, para determinar a capacidade de armazenamento do mesmo e, as lâminas de reposição foram calculadas pelo produto da Evapotranspiração de Referência com base no modelo da FAO-Penmam-Monteith (ALLEN et al., 2006) e o Coeficiente de Cultivo (Kc) determinado para o amendoim, cultivar BR1 por Almeida et al. (2017).

Para obtenção da estimativa da evapotranspiração de referência, foi instalada na área experimental uma torre micrometeorológica, constando de dois piranômetros para mediação da radiação solar global e refletida pela cultura, um saldo radiômetro para mediação do saldo de radiação, dois psicrômetros com termopares de cobre e "constantan" para medir a temperatura úmida e seca acima da copa da cultura, dois anemômetros para medir a velocidade do vento e dois fluxímetros para medir o fluxo de calor no solo.

A fonte de água foi proveniente do rio São Francisco, fornecida pela companhia que abastece os projetos irrigados da 
Codevasf. A mesma fornece água pressurizada nos lotes dos colonos 6 dias por semana.

\section{Análise de Crescimento}

Foram realizadas avaliações, aos 30, 60 e 90 dias após a emergência (DAE), em 10 plantas por parcela, onde foram determinados componentes morfológicos da cultura do amendoim: diâmetro do colmo e altura de plantas. A coleta foi realizada em 10 plantas de amendoim de cada parcela, tomando como base a região do colo da planta $( \pm 3 \mathrm{~cm}$ de altura $)$ para o diâmetro (DC), altura de planta (AP) determinação do crescimento da planta.

Foi utilizado para medir o diâmetro do colmo, paquímetro digital com precisão de $0,01 \mathrm{~mm}$; para a altura de plantas foi utilizado trena com precisão de $0,05 \mathrm{~cm}$.

\section{Determinação da produtividade}

Após os 90 dias foram colhidas 10 plantas para determinação da produtividade foram medidas o estande final de plantas de cada parcela, determinando a produtividade média para cada tratamento em cascas e em grãos, determinando-se também a quantidade de vagens com 1, 2, 3 e 4 grãos e vagens chochas (Figura 3).

O número de vagens viáveis (NV), índice de vagens (número de vagens por planta- NVP) foi calculado com base nos valores obtidos da contagem 10 plantas de amendoim, de duas fileiras centrais e em seguida fazer pelo estande final a estrapolação de produtividade para 1 ha.

Figura 3. Amostra descascadas para identificação de número de grãos por vagem e contagem das mesmas.

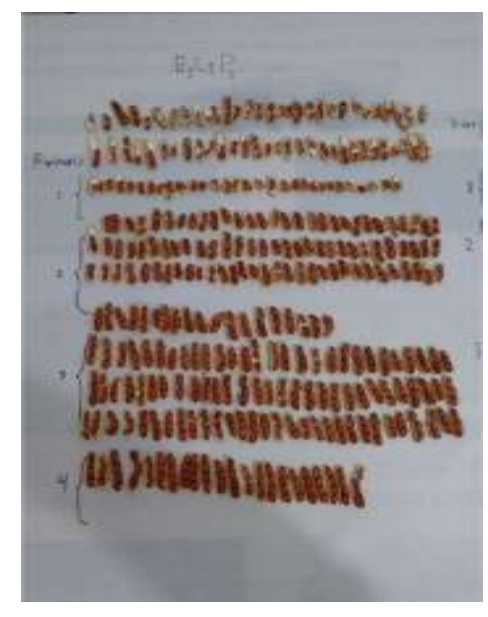

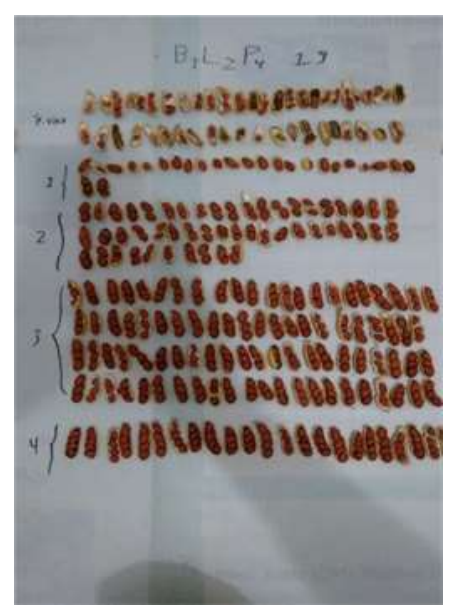

Fonte: Costa, F. A. M.

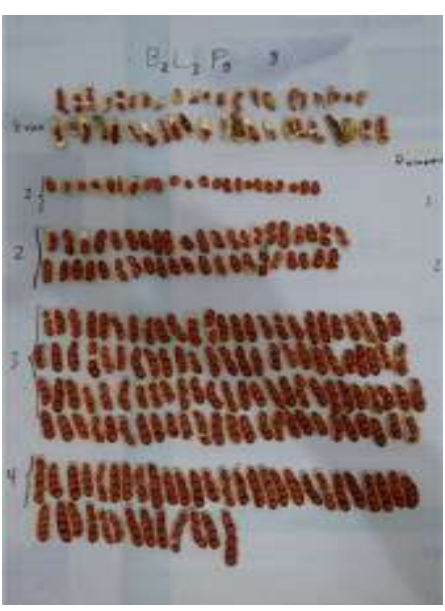

Com a coleta de dez plantas na parte central de cada subparcela, as vagens foram separadas por quantidade de grãos e pesadas separadamente, com isso foram possíveis obter indicativos se as lâminas de água inferiram algum resultado positivo ou negativo na quantidade de vagens viáveis, com três e com quatro grãos que são características do cultivar (Figura 3). Posteriormente os grãos foram pesados separadamente, depois misturados e dele retirado uma amostra para determinar a massa de 100 grãos e como somatório dos pesos foi determinado a produtividade.

Estas vagens foram descascadas a mão, e seguida foram separadas em quantidade de grãos por vagens, posteriormente foram misturadas e determinadas à massa de grãos das 10 plantas, e com o número final do estande, obtivemos de forma indireta a produtividade a $8 \%$ de umidade. 


\section{Produtividade de água}

A produtividade de água ou a eficiência no uso da água (EUA) (Kg·ha-1·mm-1) foi definida pela relação produtividade de grãos de matéria produzida pela lâmina de água aplicada, calculada pela Equação 1 (LACERDA et al., 2009).

$$
E U A=\frac{Y c}{Q a}
$$

Onde:

EUA = Eficiência de uso da Água $(\mathrm{Kg} \cdot \mathrm{m}-3)$ e ou produtividade de água;

$\mathrm{Yc}=$ Produtividade da cultura $(\mathrm{Kg} \cdot \mathrm{ha}-1)$;

$\mathrm{Qa}=$ Quantidade de água utilizada pela cultura (m3).

A Eficiência do Uso da Água para vagens comerciais EUA foi calculada pela divisão da produtividade de vagens comerciais (PVC) em kg, pela lâmina de água (em mm).

\section{Análise dos dados}

Os dados de crescimento, de produção e de eficiência do uso água foram avaliados em esquema de parcelas subdivididas. Para os fatores lâminas foi aplicado análise de regressão, por se tratar de fatores quantitativos, e os tipos de sistemas de preparo convencional do solo teste de Tukey, fator qualitativo, utilizando-se o programa computacional SISVAR (Ferreira, 2014).

\section{Resultados e Discussão}

\section{Análise de crescimento $1^{\circ}$ Ciclo - junho a agosto de 2015}

$\mathrm{Na}$ análise de variância o fator sistemas de preparo convencional do solo (SP) para as variáveis altura de planta (AP) e diâmetro de caule (DC) durante todo o período amostral não tiveram variação estatística significativa. Enquanto que para o fator lâminas de irrigação (L) para altura de planta e o diâmetro de caule aos 60 DAE foram estatisticamente significativas a $1 \%$, Tabela 1, época em que a planta estava no estágio intermediário, ou seja, em florescimento, formação e alongamento do ginóforo e formação de vagens. 
Tabela 1. Análise de variância (ANAVA) para altura de planta e diâmetro de caule do amendoinzeiro aos 30 , 60 e 90 após a emergência sob diferente sistema de preparo convencional do solo e lâminas de irrigação.

\begin{tabular}{|c|c|c|c|c|c|c|c|}
\hline \multirow[b]{3}{*}{ Fonte de variação } & \multirow[b]{3}{*}{ GL } & \multicolumn{5}{|c|}{ Quadrado Médio } & \multirow[b]{3}{*}{90 Dias } \\
\hline & & \multicolumn{3}{|c|}{ Altura de planta } & \multicolumn{2}{|c|}{ Diâmetro de caule } & \\
\hline & & 30 Dias & 60 Dias & 90 Dias & 30 Dias & 60 Dias & \\
\hline SP & 3 & $1,80 \mathrm{~ns}$ & $53,48 \mathrm{~ns}$ & $75,44 \mathrm{~ns}$ & $0,286 \mathrm{~ns}$ & $0,25 \mathrm{~ns}$ & $10,26 \mathrm{~ns}$ \\
\hline Resíduos & 9 & 1,83 & 36,40 & 39,15 & 0,08 & 0,245 & 0,18 \\
\hline $\mathrm{L}$ & 3 & $1,87 \mathrm{~ns}$ & $109,1 *$ & $34,6 \mathrm{~ns}$ & $0,34 \mathrm{~ns}$ & $0,99 *$ & $0,053 \mathrm{~ns}$ \\
\hline Regressão linear & 1 & - & $135,2 *$ & - & - & $0,16 \mathrm{~ns}$ & - \\
\hline $\begin{array}{l}\text { Regressão } \\
\text { quadrática }\end{array}$ & 1 & - & $107,87 \mathrm{~ns}$ & - & - & $0,00056 \mathrm{~ns}$ & - \\
\hline Desvio & 1 & - & $84,23 \mathrm{~ns}$ & - & - & $2,8 * *$ & - \\
\hline SP x L & 9 & $1,72 \mathrm{~ns}$ & $17,39 \mathrm{~ns}$ & $25,84 \mathrm{~ns}$ & $0,05 \mathrm{~ns}$ & $0,32 \mathrm{~ns}$ & $0,61 \mathrm{~ns}$ \\
\hline Residuos & 36 & 1,67 & 28,85 & 41,15 & 0,21 & 0,28 & 0,29 \\
\hline $\mathrm{CV}(\mathrm{SP})-\%$ & & 24,72 & 34,63 & 30,92 & 7,28 & 10,29 & 8,38 \\
\hline $\mathrm{CV}(\mathrm{L})-\%$ & & 23,64 & 30,83 & 31,70 & 11,64 & 11,13 & 10,58 \\
\hline
\end{tabular}

Fonte: Costa, F. A. M.

Segundo Ferrari Neto et al. (2012) as plantas possuem hábito indeterminado de crescimento, ocorrendo simultaneamente o desenvolvimento vegetativo e o reprodutivo. Silva e Beltrão (2000) relatam que o déficit hídrico pode interferir negativamente o conjunto das funções fisiológicas da planta, como a fotossíntese, respiração e outras reações metabólicas, podendo repercutir diretamente nas variações anatômicas (estômatos), no crescimento, na reprodução e no desenvolvimento das plantas, de modo geral, particularmente nos frutos e sementes, além da produtividade. Na Figura 4, observa-se que a lâmina de 75\% ETC teve maior altura de planta aos 60 DAE, assim ao aumentar a quantidade de água houve plantas com menores alturas. 
Figura 4. Altura de planta $(\mathrm{cm})$ de amendoim BR-01 em função das lâminas de irrigação aos 60 dias após a emergência submetidos a diferentes tipos de sistema de plantio convencional.

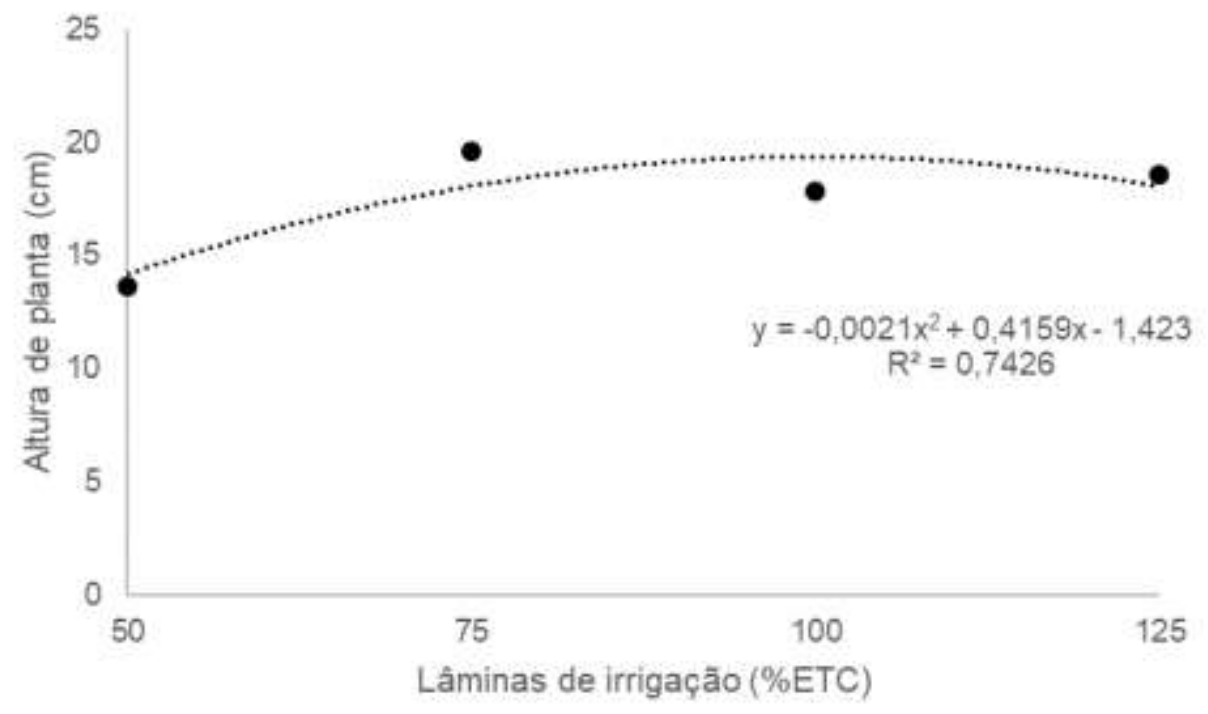

Fonte: Costa, F. A. M.

Alexandre Junior et al. (2010) encontrou que a lâmina de 100\% da necessidade hídrica da cultura foi a que apresentou um maior desenvolvimento da cultura. Ferreira et al. (1992) encontra redução na altura das plantas de amendoim, em condições de estresse hídrico, quando comparado as plantas que não sofreram diminuição de ETc.

Os amendoinzeiro são rigorosos em água, segundo Alexandria Junior et al. (2010) a cultivar BR1 submetida a diferentes laminas de água, tiveram resultados satisfatórios de altura de planta com as lâminas de $125 \%$ da ET0 e $50 \%$ da ET0.

Marines (2012) afirmam que para as plantas de amendoim se desenvolverem de maneira adequada devem ser irrigadas com $200 \%$ a $250 \%$ do total de água evaporada.

Para o diâmetro de caule aos 60 DAE, constata-se na Figura 5 que o maior diâmetro foi obtido com aplicação de $100 \%$ ETC na irrigação. A planta teve dificuldade de crescimento principalmente para lâmina de 50\%, sugerindo um melhor desenvolvimento para lâmina de $100 \%$ da ETc. 
Figura 5. Diâmetro de caule $(\mathrm{mm})$ de amendoim BR-01 em função das lâminas de irrigação aos 60 dias após emergência submetidos a diferentes sistemas de preparo convencional do solo.

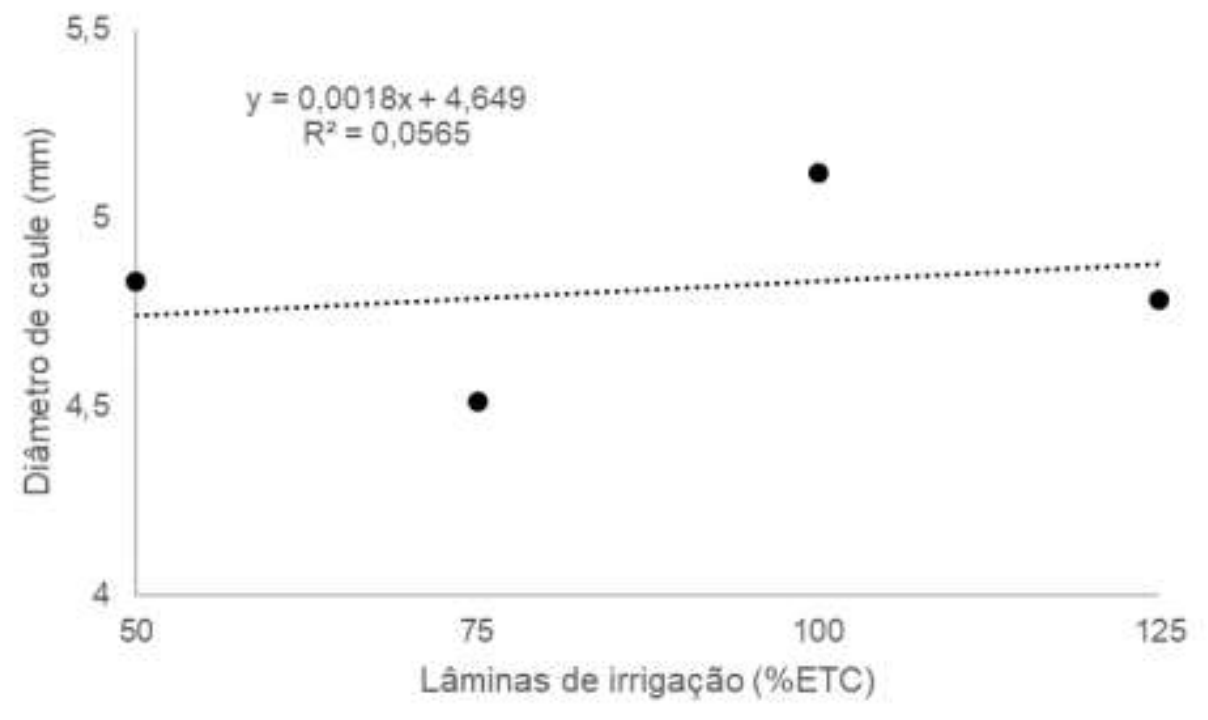

Fonte: Costa, F. A. M.

\section{Produtividade do amendoim - $1^{\circ}$ Ciclo}

- Porcentagem de grãos por vagem (PGV)

Dentre os tratamentos estudados observou-se que não houve variação significativa para a porcentagem de grãos por vagens para nenhum dos fatores analisados. Mesmo não havendo variação significativa entre os sistemas de preparo de solo, na Tabela 2, constata-se que as plantas que continham 3 grãos por vagem foram as que obtiveram maiores valores médios, ratificando o padrão da variedade plantada (BR-1). Houve significância a 5\% na interação do sistema de preparo convencional do solo e as lâminas de irrigação aplicada no amendoim. 
Tabela 2. Porcentagem de grãos por vagens para o $1^{\circ}$ ciclo do amendoinzeiro submetido a lâminas de irrigação e diferentes sistemas de preparo convencional do solo.

\begin{tabular}{|c|c|c|c|c|c|}
\hline \multicolumn{6}{|c|}{ Quadrado Médio - Grãos por vagem (\%) } \\
\hline Fonte de variação & GL & 1 grão & 2 grãos & 3 grãos & 4 grãos \\
\hline SP & 3 & $0,31 \mathrm{~ns}$ & $65,98 \mathrm{~ns}$ & $55,21 \mathrm{~ns}$ & $19,94 \mathrm{~ns}$ \\
\hline Resíduos & 9 & 2,17 & 21,62 & 29,65 & 7,36 \\
\hline $\mathrm{L}$ & 3 & $0,28 \mathrm{~ns}$ & $25,58 \mathrm{~ns}$ & $41,89 \mathrm{~ns}$ & $32,66 \mathrm{~ns}$ \\
\hline Regressão linear & 1 & - & - & - & - \\
\hline $\begin{array}{l}\text { Regressão } \\
\text { quadrática }\end{array}$ & 1 & - & - & - & - \\
\hline Desvio & 1 & - & - & - & - \\
\hline SP $x$ L & 9 & $3,01 \mathrm{~ns}$ & $34,8 *$ & $34,38 \mathrm{~ns}$ & $7,87 \mathrm{~ns}$ \\
\hline Resíduos & 36 & 1,55 & 12,74 & 18,57 & 13,14 \\
\hline CV (SP) - \% & & 33,85 & 24,98 & 17,03 & 28,49 \\
\hline CV (L) - \% & & 28,57 & 18,46 & 13,47 & 38,06 \\
\hline \multicolumn{6}{|l|}{$\begin{array}{l}\text { Preparo } \\
\text { convencional }\end{array}$} \\
\hline SP1 & & $4,41 \mathrm{a}$ & $19,45 a$ & $34,48 a$ & $9,47 \mathrm{a}$ \\
\hline SP2 & & $4,23 \mathrm{a}$ & $21,94 a$ & $30,08 \mathrm{a}$ & $8,57 \mathrm{a}$ \\
\hline SP3 & & $4,53 \mathrm{a}$ & $17,00 \mathrm{a}$ & $32,06 \mathrm{a}$ & $11,1 \mathrm{a}$ \\
\hline SP4 & & $4,25 \mathrm{a}$ & $18,97 \mathrm{a}$ & $31,29 a$ & $8,95 \mathrm{a}$ \\
\hline
\end{tabular}

Fonte: Costa, F. A. M.

Analisando o cultivo de amendoim, Souza et al. (2012) relataram que em todos os períodos, os genótipos tiveram diminuição na produção em quantidade de vagem.

Quando observa-se a interação dos tratamentos, constata-se na Figura 6, que o sistema de preparo do solo com grade aradora e grade intermediária de 14 discos (SP2) com lâminas de 100\% ETc, houve maior porcentagem de vagens com 2 grãos, cerca de $28 \%$. As menores porcentagens foram obtidas com lâminas de $75 \%$ ETc relacionado com sistema de preparo do solo com arado escarificador seguido de grade niveladora (SP3) e o SP4 (Preparo do solo com arado escarificador seguido de grade aradora). 
Figura 6. Desdobramento da interação sistema de preparo convencional do solo e lâminas de irrigação submetidas ao cultivo de amendoim cultivar BR-1, Petrolândia - PE.

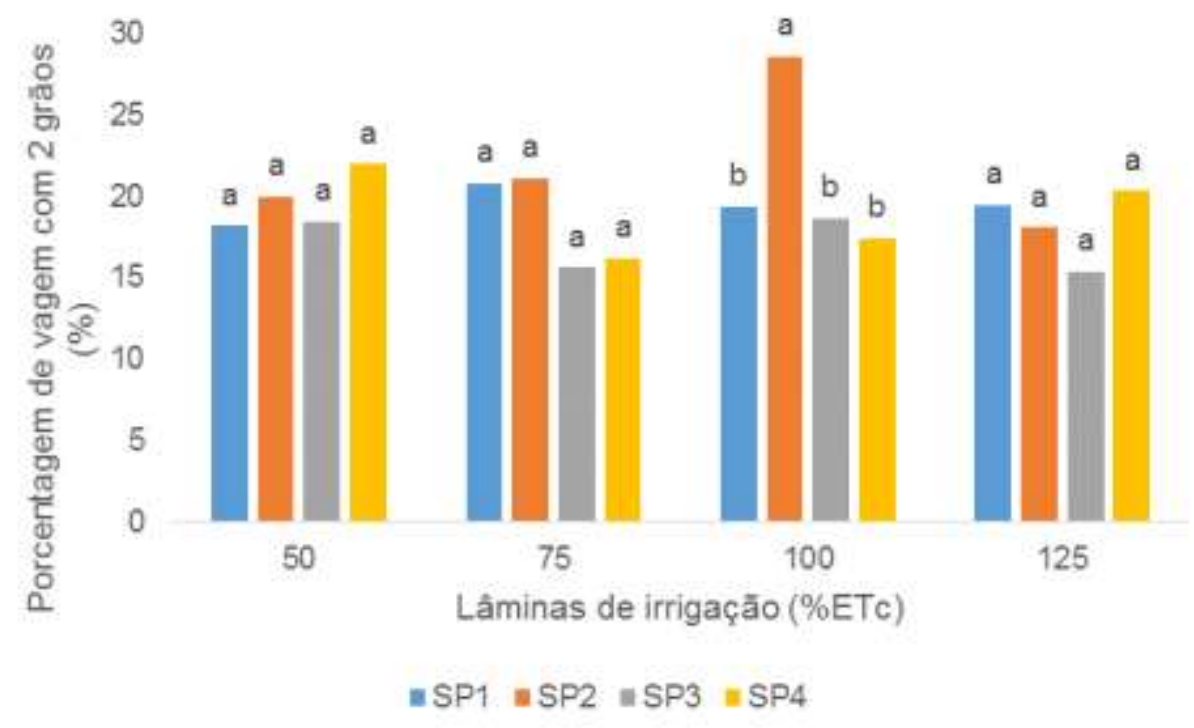

Fonte: Costa, F. A. M.

Na Tabela 3, nota-se que não houve variação significativa para vagens chochas para o fator de variação diferentes sistemas de preparo convencional do solo. Para porcentagem de casca houve significância estatística a 5\% para preparo convencional do solo. O SP1 teve uma porcentagem de vagens chochas menor na comparação com o SP4, este fato tenha ocorrido provavelmente pela menor resistência que os ginóforos tiveram ao desenvolver-se nesse sistema de preparo. Uma vez que, quanto menor for à quantidade de vagens chochas menores será a porcentagem de cascas, e neste caso, o SP1 teve a menor quantidade de casca (Tabela 3).

Para as lâminas de irrigação houve variação significativa para vagens chochas a 5\%, enquanto que para cascas não ocorreu significância estatística (Tabela 3). A porcentagem de vagens chochas e cascas estão relacionadas, uma vez que, quanto maior for à quantidade de vagens chochas maior será a quantidade de cascas, interferindo na produtividade final com aumento em casca. 
Tabela 3. Produção de vagens chochas e cascas para o $1^{\circ}$ ciclo da cultura de amendoim submetidos a lâminas de irrigação e sistemas de preparo do solo convencional.

\begin{tabular}{|c|c|c|c|}
\hline & & Quadrado médio & \\
\hline Fator de variação & GL & Vagens chochas (\%) & Cascas $(\%)$ \\
\hline SP & 3 & $5,49 \mathrm{~ns}$ & $27,64 *$ \\
\hline Resíduos & 9 & 2,77 & 4,58 \\
\hline $\mathrm{L}$ & 3 & $13,57 *$ & $113,00 \mathrm{~ns}$ \\
\hline Regressão linear & 1 & $13,7 \mathrm{~ns}$ & - \\
\hline $\begin{array}{l}\text { Regressão } \\
\text { quadrática }\end{array}$ & 1 & $14,84 *$ & - \\
\hline Desvio & 1 & $12,15 \mathrm{~ns}$ & - \\
\hline SP x L & 9 & $7,06 \mathrm{~ns}$ & $9,53 \mathrm{~ns}$ \\
\hline Residuos & 36 & 3,45 & 7,57 \\
\hline CV (SP) - \% & & 29,21 & 7,36 \\
\hline CV $(\mathrm{L})-\%$ & & 32,59 & 9,46 \\
\hline \multicolumn{4}{|l|}{$\begin{array}{l}\text { Preparo } \\
\text { convencional }\end{array}$} \\
\hline SP1 & & $4,9 \mathrm{a}$ & $27,27 b$ \\
\hline SP2 & & $5,66 \mathrm{a}$ & $29,5 \mathrm{ab}$ \\
\hline SP3 & & $6,13 \mathrm{a}$ & $29,16 a b$ \\
\hline SP4 & & $6,13 \mathrm{a}$ & $30,4 \mathrm{a}$ \\
\hline
\end{tabular}

Fonte: Costa, F. A. M.

Valores inferiores foram observados por Santos er al. (2009) para variedade de amendoim BR-1, com cerca de 12\% de vagens chocas e para variedade Tatu aproximadamente $15 \%$.

Averiguando a Figura 6, observa-se que ao aumentar a disponibilidade hídrica (100 e 125\% ETC) à cultura de amendoim houve um incremento na quantidade de vagens chocas, contudo a lâmina de 75\% ETC teve médias inferiores aos demais aplicados, sendo esta lâmina indicada para menor produção de vagens chocas. Para comercialização e rendimento da produção quanto menor a quantidade de vagens chocas e de cascas, maior será a produção rentável ao agricultor. 
Figura 7. Regressão da porcentagem de vagens chochas em função das lâminas de irrigação submetidas a preparo convencional do solo, Petrolândia - PE.

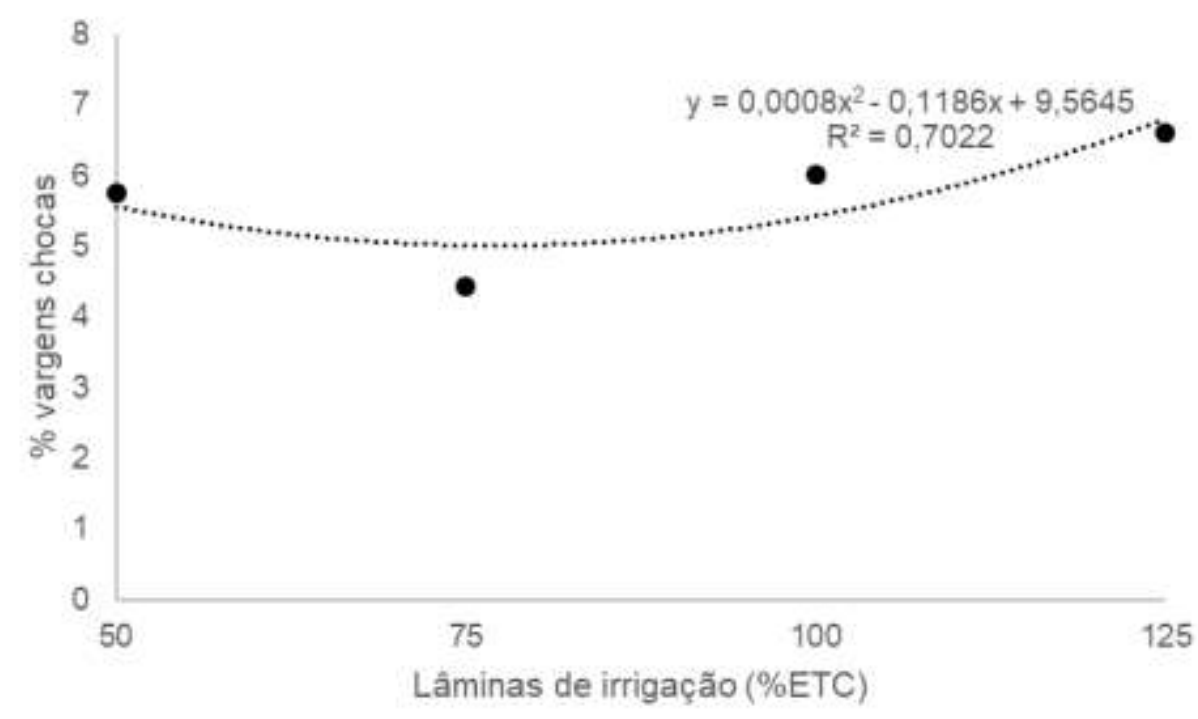

Fonte: Costa, F. A. M.

Silva et al. (1998) em estudo similar em projeto irrigado no município de Rodelas-BA encontrou uma porcentagem de vagens chochas similar a este trabalho que também foi influenciada tanto pela lâmina quanto pelo intervalo de irrigação, variando de 3,5 a 8,5\% na lâmina de 300 mm, de 3,75 a 4,75\% na lâmina de 500 mm e de 1,75 a 4,75\% na lâmina de 700 mm.

\section{Peso de 100 grãos e produtividade de água (EUA) no ciclo 1}

O peso de 100 grãos foi significativo $(\mathrm{p}<0,01)$ para fonte de variação lâminas de irrigação, mesmo não sendo significativo o sistema de preparo convencional do solo, a maior média registrada foi com SP1. A eficiência de uso da água para sem casca foi significativo $(\mathrm{p}<0,05)$ para sistema de preparo convencional do solo e EUA sem casca e com casca foi significativo a $1 \%$ para fator de variação lâminas de irrigação, Tabela 4.

O sistema de preparo convencional do solo que teve média elevada para a variável EUA com e sem casca foi SP1, seguido pelo SP2. Ao comparar SP1 com menor valor obtido SP4 para EUA sem casca, houve acréscimos de aproximadamente $22 \%$ na eficiência de uso da água, devido apenas o tipo de preparo aplicado na área. Analisando EUA com casca a menor média foi proveniente do SP3, relacionando SP1 com SP3, tem-se elevação de EUA de 16,12\%, Tabela 4. Desse modo o SP1 ou SP2, são os tipos de preparo do solo indicado para obter elevada taxa de produtividade de água no cultivo de amendoim. 
Tabela 4. Análise de variância do peso de 100 grãos e eficiência de uso da água de amendoim BR-01 com casca e sem casca no $1^{\circ}$ ciclo, submetido a diferentes lâminas de irrigação e preparo convencional do solo.

$$
\text { Quadrado médio }
$$

\begin{tabular}{|c|c|c|c|c|}
\hline & & & \multicolumn{2}{|c|}{ Eficiência de Uso da Água (EUA) } \\
\hline Fator de variação & GL & Peso 100 grãos & Sem casca & Com casca \\
\hline SP & 3 & $15,05 \mathrm{~ns}$ & $28,30 *$ & $41,07 \mathrm{~ns}$ \\
\hline Resíduos & 9 & 8,61 & 5,70 & 13,35 \\
\hline $\mathrm{L}$ & 3 & $150,13 * *$ & $317,4 * *$ & $731,04 * *$ \\
\hline Regressão linear & 1 & $444,24 * *$ & $921,67 * *$ & $2112,6 * *$ \\
\hline $\begin{array}{l}\text { Regressão } \\
\text { quadrática }\end{array}$ & 1 & $4,11 \mathrm{~ns}$ & $17,12 \mathrm{~ns}$ & $72,4^{*}$ \\
\hline Desvio & 1 & $2,03 \mathrm{~ns}$ & $13,4 \mathrm{~ns}$ & $8,16 \mathrm{~ns}$ \\
\hline $\begin{array}{l}\text { INTERAÇÃO SP } \\
x \text { L }\end{array}$ & 9 & $6,62 \mathrm{~ns}$ & $13,39 \mathrm{~ns}$ & $17,53 \mathrm{~ns}$ \\
\hline Resíduos & 36 & 3,37 & 6,77 & 14,25 \\
\hline $\mathrm{CV}(\mathrm{SP})-\%$ & & 6,54 & 17,10 & 17,11 \\
\hline $\mathrm{CV}(\mathrm{L})-\%$ & & 4,09 & 18,63 & 17,68 \\
\hline $\begin{array}{l}\text { Preparo } \\
\text { convencional }\end{array}$ & & (g) & (Kg.m-3) & $(\mathrm{Kg} \cdot \mathrm{m}-3)$ \\
\hline SP1 & & $45,58 \mathrm{a}$ & $15,18 \mathrm{a}$ & $22,90 \mathrm{a}$ \\
\hline SP2 & & $43,44 a$ & $14,91 \mathrm{ab}$ & $22,54 \mathrm{a}$ \\
\hline SP3 & & $45,25 \mathrm{a}$ & $13,4 \mathrm{ab}$ & $19,72 \mathrm{a}$ \\
\hline SP4 & & $45,23 \mathrm{a}$ & $12,35 b$ & $20,24 a$ \\
\hline
\end{tabular}

Fonte: Costa, F. A. M.

Santos et al. (2009) analisando as características agronômicas e tecnológicas da cultivar BR-1, relataram que o peso de 100 sementes ou grãos de amendoim podem atingir cerca de 48 gramas, dessa maneira para os sistemas de preparo convencional do solo nesta pesquisa os valores ficaram inferiores aos destes pesquisadores, contudo é superior a cultivar Tatu (42 g). Resultado divergente foi obtido por Ribeiro et al. (2018) em sua pesquisa com genótipos de amendoim obtendo para a variável peso 100 grãos uma média de 79,8 g, valor bem superior aos dados médios deste estudo, o que pode ser levado em consideração esta diferença pelas características dos genótipos. Na Figura 8, constata-se que o modelo que se adequou foi o linear com $\mathrm{R}=98 \%$, sendo diretamente proporcional o peso dos grãos a quantidade de água aplicada na irrigação, com maior média pra lâmina de $125 \%$ ETC. 
Figura 8. Análise de regressão do peso de 100 grãos de amendoim BR-01 com casca e sem casca em função das lâminas de irrigação com diferentes sistemas de preparo do solo, Petrolândia - PE.

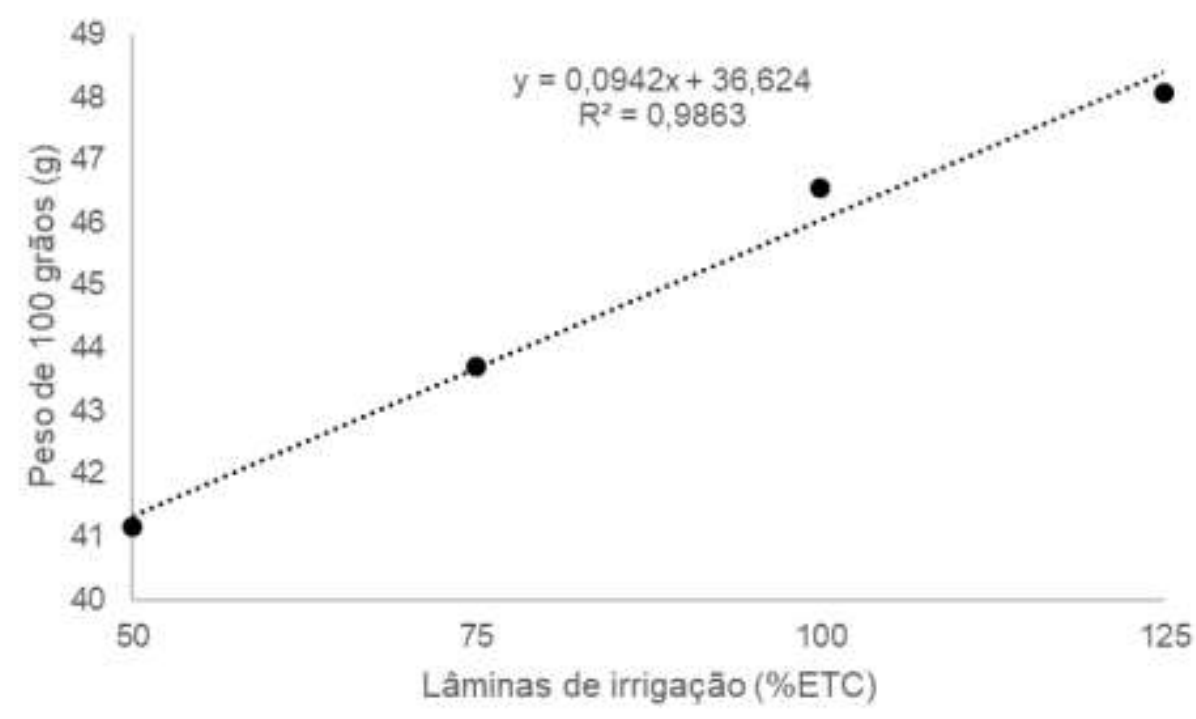

Fonte: Costa, F. A. M.

A eficiência de uso da água do amendoim, há um declínio com elevação da quantidade de água aplicada (Figura 9), sendo a maior taxa de eficiência com aplicação de 50\% ETC, sendo esta quantidade de irrigação indicada para maior EUA tanto sem casca como com casca, com equação linear em ambas as situações.

Figura 9. Análise de regressão da eficiência de uso da água sem casca de amendoim BR-01 com casca e sem casca em função das lâminas de irrigação com diferentes sistemas de preparo do solo, Petrolândia - PE.

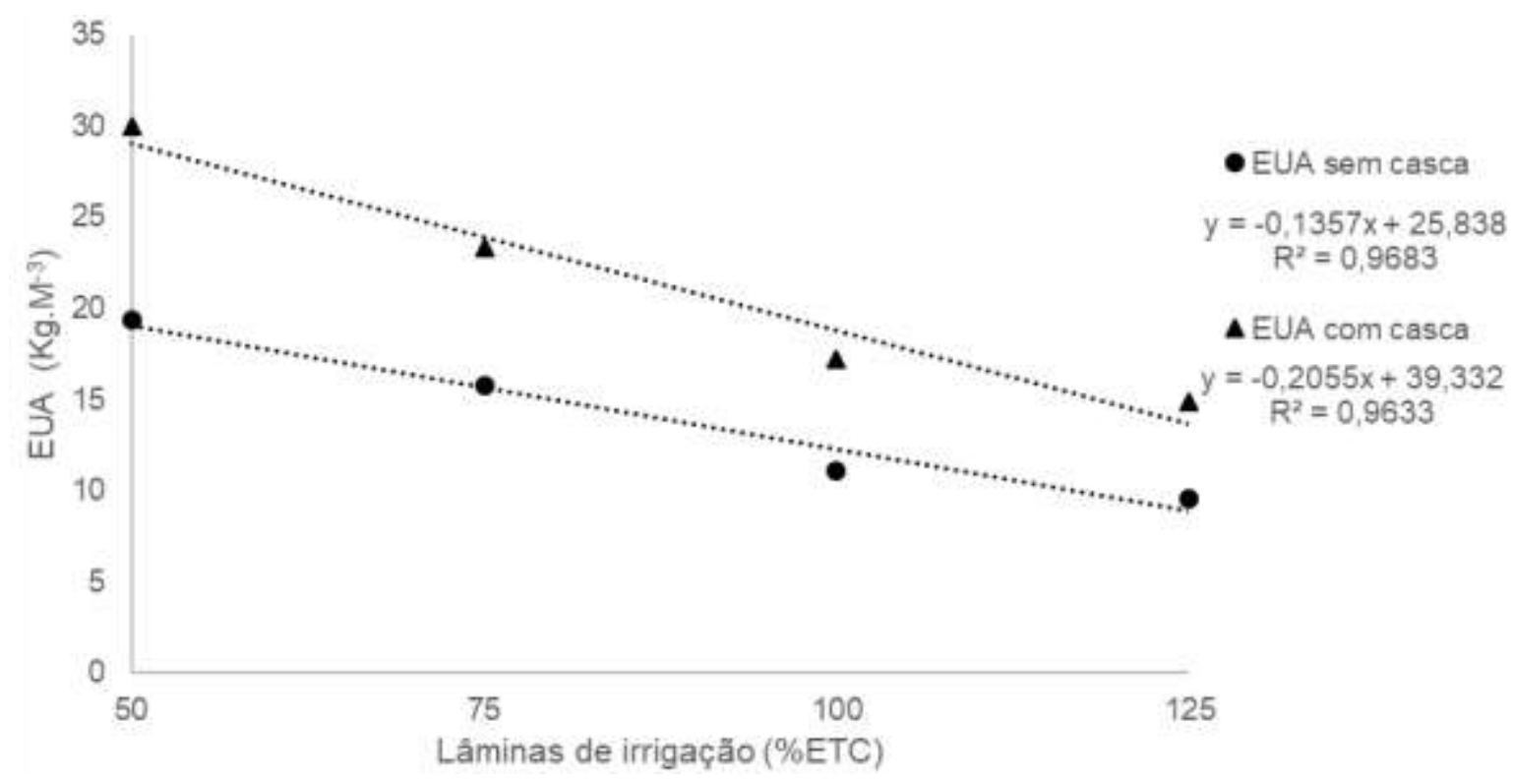

Fonte: Costa, F. A. M. 


\section{Conclusão}

Os sistemas de preparo do solo não influenciam o crescimento da cultura do amendoim;

As lâminas de água influenciam o desenvolvimento vegetativo no período logo após a floração, com maior altura de planta ao aplicar elevada quantidade de água na irrigação;

A produtividade do amendoim tem maior produção com sistema de preparo convencional do solo SP2 (Preparo do solo com grade aradora e Grade intermediária de 14 discos) no $1^{\circ}$ ciclo;

A produção com e sem casca no $1^{\circ}$ ciclo teve maior média com aplicação de $125 \%$ ETc (L4);

A lâmina de $50 \%$ da necessidade hídrica teve melhor eficiência de uso da água no $1^{\circ}$ ciclo do amendoim BR-1;

O SP3 é o tipo de preparo indicado para obtenção de maior acréscimo de produção, obtendo em torno de 177 sacas;

No $1^{\circ}$ ciclo o sistema de preparo convencional do solo SP4 junto com a lâmina L2 (75\% ETc) tiveram maior receita liquida;

\section{Referências}

Alexandria Junior, F. F. de., Pereira, C. J. G. S. de., Castro, M. A. do N., Quesado, F. das C., \& Leite, A. G. (2010). Crescimento do amendoim BR1 em diferentes lâminas de irrigação. IV Congresso Brasileiro de Mamona e I Simpósio Internacional de Oleaginosas Energéticas, João Pessoa, PB.

Allen, R. G., Pereira, L. S., Raes, D., \& Smith, J. (2006). Evapotranspiration del cultivo: guias para la determinación de los requerimientos de água de los cultivos. Roma: FAO. 298 p.

Araújo Filho, J. C., Burgos, N., Lopes, O. F., Silva, F. H. B. B., Medeiros, L. A. R., Melo Filho, H. F. R., Parahyba, R. B. V., Cavalcanti, A. C., Oliveira Neto, M. B., Silva, F. B. R., Leite, A. P., Santos, J. C. P., Sousa Neto, N. C., Silva, A. B., Luz, L. R. Q. P., Lima, P. C., Reis, R. M. G., \& Barros, A. H. C. (2000). Levantamento de reconhecimento de baixa e média intensidade dos solos do Estado de Pernambuco. Rio de Janeiro: Embrapa Solos. (Embrapa Solos, Boletim de Pesquisa; 11)

Bastos, F. J. C., Rocha, A. C., Furtado, N. S., Cunha, F. N., Carreira, F. S., \& Carvalho, T. L. (2012). Desempenho de cultivares e linhagens de amendoim irrigado no sudoeste do Estado de Goiás. Inovagri Meeting.

Bolonhezi, D., Mutton, M. A. E., \& Martins, A. L. M. (2007). Sistemas conservacionistas de manejo do solo para amendoim cultivado em sucessão à cana crua. Pesquisa agropecuária brasileira, Brasília, 42(7), 939-947.

CFSEMG - Comissão de Fertilidade do Solo do Estado de Minas Gerais. Recomendações para o uso de corretivos e fertilizantes em Minas Gerais. $4^{\mathrm{a}}$ aproximação, Lavras: 1989. 176p.

Cortez, J. W., Alves, A. D. S., Moura, R. D., Olszevski, N., \& Nagahama, H. J. (2011). Atributos físicos do Argissolo amarelo do semiárido nordestino sob sistemas de preparo. Revista Brasileira de Ciência do Solo, Viçosa, 35(4), 1207-1216.

Costa, J. D., \& Sichmann, W. (1972). Cultura do amendoim. ESALQ, Piracicaba, 16 p.

Durães, F. O. M., Magalhães, P. C., \& Oliveira, A. C. (2002). Índice de colheita genético e as possibilidades da genética fisiológica para melhoramento do rendimento de milho. Revista Brasileira de Milho e Sorgo. 1(1), 33-40.

EMPRESA BRASILEIRA DE PESQUISA AGROPECUÁRIA. Centro Nacional e Pesquisa em Solos. Sistema Brasileiro de Classificação de Solos. Rio de Janeiro: Embrapa-Solos, 2006. 306 p.

Ferrari Neto, J., Costa, C. H. M. da., \& Castro, G. S. A. (2012). Ecofisiologia do amendoim. Scientia Agraria Paranaensis, 11(4), 1-13.

Frizzone, J. A. (2007). Planejamento da Irrigação com uso de técnicas de otimização. Revista Brasileira de Agricultura Irrigada, CE, INOVAGRI. 1(1), 24 49.

Inforzato, R., \& Tella, R. (1960). Sistema radicular do amendoim. Campinas: Bragantia, n. 19, p. 119-123.

Lacerda, C. F., Neves, A. L. R., Guimarães, F. V. V., Silva, F. L. B., Prisco, J. T., \& Gheyi, H. R. (2009). Eficiência de utilização de água e nutrientes em plantas de feijão-de-corda irrigadas com água salina em diferentes estádios de desenvolvimento. Engenharia Agrícola, v. 29, p.221-230.

Marines, R. O. (2012). Manejo da irrigação da cultura do amendoim Arachis hypogaea com base na evaporação. Revista Brasileira de Energias Renováveis, 1(1), 33-41.

Ministério da Agricultura. Levantamento exploratório - reconhecimento de solos do Estado de Pernambuco. Recife: SUDENE, 1973. 354 p (SUDENE. Boletim técnico $\left.\mathrm{n}^{\mathrm{o}} 26\right)$.

Nakagawa, J., \& Rosolém, C. A. (2011). O amendoim: tecnologia de produção. Bauru: Fepaf.

Nakagawa, J., Lasca, D. de C., Neves, G. de S., Neves, J. P. de S., Silva, M. N., Sanches, S. V., Barbosa, V., \& Rossetto, C. A. V. (2000). Densidade de plantas e produção de amendoim. Sciencia Agricola, 57 (1), Piracicaba. 
Research, Society and Development, v. 10, n. 13, e246101321233, 2021

(CC BY 4.0) | ISSN 2525-3409 | DOI: http://dx.doi.org/10.33448/rsd-v10i13.21233

Peixoto, C. P., Camara G. M. S., Martins, M. C., \& Marchiori, L. F. S. (2002). Efeitos de épocas de semeadura e densidade de plantas sobre a produtividade de cultivares de soja no Estado de São Paulo. Revista de Agricultura, Piracicaba, 77(2), 265-291.

Peixoto, C. P., Gonçalves, J. A., Peixoto, M. de F. da S. P., \& do Carmo, D. O. (2008). Características agronômicas e produtividade de amendoim em diferentes espaçamentos e épocas de semeadura no recôncavo baiano. Bragantina, 67(3), 673 - 684 .

Ribeiro, R. P., Suassuna, T. M. F., Heuert, J., Soave, J. H., \& Santos, L. C. C. (2018). Desempenho de genótipos de amendoim na Alta Paulista. Researchgate, $1(1), 1-5$.

Santos, R. C., Moreira, J. A. N., Valle, L. V., Freire, R. M. M., Almeida, R. P., Araújo, J. M., \& Silva, L. C. (2009). Amendoim BR-1 - Informações para seu cultivo. Embrapa Algodão.

Silva, L. C., \& Beltrão, N. E. de M. (2000). Incremento de fitomassa e produtividade do amendoinzeiro em função de lâminas e intervalos de irrigação. Revista Brasileira de Oleaginosas e Fibrosas, Campina Grande, 4(2), 111-121.

Silva, L. C., Beltrão, N. E. de M., Rao, T. V. R., \& Filho, J. F. (1998). Efeito do Manejo da irrigação na qualidade da produção e na produtividade do amendoim cv. BR1. Revista Brasileira de Engenharia Agrícola e Ambiental, 2(2), 175-178.

Távora, F. J. A. F., \& Melo, F. I. O. (1991). Resposta de cultivares de amendoim a ciclos de deficiência hídrica: crescimento vegetativo, reprodutivo e relações hídricas. Ciência Agronômica, Fortaleza, 22(1/2), 47-60. 